\title{
An Education Literature Review on Digitization, Digitalization, Datafication, and Digital Transformation
}

\author{
Man Zhao ${ }^{1,2}$ Han-Teng Liao ${ }^{1,2, *}$ Si-Pan Sun ${ }^{1}$ \\ ${ }^{1}$ School of Literature and Communication, Sun Yat-sen University Nanfang College, Guangzhou, Guangdong, 510970, China \\ ${ }^{2}$ New Media Research Centre, Sun Yat-sen University Nanfang College, Guangzhou, Guangdong, 510970, China \\ *Corresponding author.Email: h.liao@oxon.org
}

\begin{abstract}
Digital innovation and transformation provide opportunities in both education and workplace environments, raising the importance of digital competencies in an increasingly digitalized world. Such importance has been heightened by the recent COVID-19 outbreak. To explore the related discussions in the education literature, this article conducts a scientometric analysis of 782 articles collected from the Web of Science (WoS) database. By examining the main sources and keywords, it shows several cross-disciplinary research fronts that involves disciplines such as engineering, management, communication, etc., and topics such as collaboration, digital economy, digital platform, etc. Also, the digital transformation research has signaled a shift from technology to organization and people. The findings offer a preliminary roadmap for educators, researchers, and policymakers how more sustainable livelihood and life potentials can be achieved by harnessing digital potentials.
\end{abstract}

Keywords: digital, digital transformation, education

\section{INTRODUCTION}

Digital innovation and transformation provide opportunities not only for education, but also for the livelihood and life potentials. Such opportunities include learning and applying digital competencies in a world that has been increasingly digitalized[1]. Consequently, major policies and programs have been designed to enhance more inclusive and equitable provision of education through digital means, such as Open Education Resources (OER)[2]. Still, as the progress of digital transformation has not yet distributed globally [3], it is necessary to understand how digital transformation can help deliver sustainable livelihood and lifestyles through both formal education and workforce training.

The need for such digital efforts has become even more pronounced when the COVID-19 outbreak has resulted in school closures that have affected 188 countries and $91.3 \%$ of the world's student population[4]. In response, distance learning solutions and recommendations have been made by the UNESCO-led coalition to utilize digital learning platforms, mobile phones, massive open online courses, etc., to alleviate the situation[5]. Similarly, when the outbreak also has cost the one-third of US labor force and its livelihood[6], it is imperative to digitally transform our environments for education and work[7]. More than ever before, people need digital competencies and capabilities to work, learn, give care and receive care from home.

We need to better understand how digitalization and digital transformation works better for more equitable education and sustainable livelihood. To contribute to that cause, this article presents a review of the education literature in relation to the concepts of digitization, digitalization, datafication and digital transformation.

\section{DATA AND METHODS}

To systematically collect relevant literature, the search query below was executed on the Web of Science (WoS):

TS = ("digiti*ation" OR "digitali*ation" OR "digital transformation" OR "datafication") AND (SU="Education \& Educational Research" OR WC=("Education \& Educational Research" OR "Education, Scientific Disciplines" OR "Education, Special" OR "Psychology, Educational")

Our search topics (see TS above) cover different spelling of the key concepts. With the scope of several indexes (SCIEXPANDED, SSCI, A\&HCI, CPCI-S, CPCI-SSH, ESCI), a total of 782 articles were collected on March 10, 2020. Python scripts were developed to extract the data, and then visualized and analyzed using VOSviewer.

As shown in Figure 1, the year 2015 marks a milestone for the increasing number of publications.

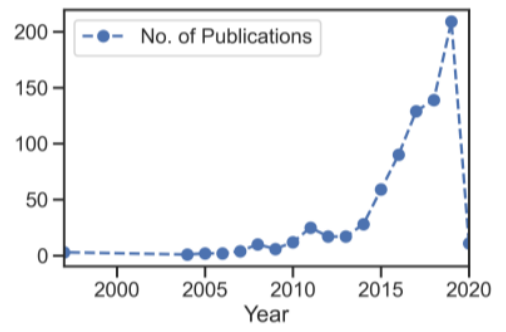

Figure 1 The number of publications 
Before 2014, the number of publications each year had been below 28 papers. However, since 2015, it has increased rapidly, and 209 papers have been published on the topic in 2019 alone.

\section{RESEARCH FINDINGS}

To explore the literature, the main publication venues, disciplines, keywords, and topics are presented as follows:

\subsection{Main clusters of publication venues and disciplines}

Conference proceedings dominate the top publication venues, as evidenced by Table 1 , showing top 6 sources are all conference sources with four of them having more than 40 papers. (The number in parentheses indicate the ranking.) The top journals include Learning Media and Technology (at the 7th place) and Comunicar (at the 9th).

Our cluster analysis, based on bibliographic coupling [8], shows one important aspect of the relationships among these top sources, as indicated by the clusters visualized in Figure 2. Providing additional information, Table 2 summarizes the number of articles, the related keywords and disciplines of these clusters. By design, education research dominates. Other disciplines include engineering, management, communication, etc., indicating several crossdisciplinary research fronts. Again, conference publications dominate, especially in clusters \#1 where all except the Inf. Technol. Learn. Tools.

\section{Table 1 Top 20 main publication sources}

\begin{tabular}{|c|c|c|}
\hline Conference and Journal Sources & Abbreviations & No \\
\hline (1) International Business Information Management Association & IBIMA & 62 \\
\hline (2) International Technology, Education and Development Conference & INTED & 58 \\
\hline (3) Annual International Conference of Education, Research and Innovation & ICERI & 41 \\
\hline (4) International Conference on Education and New Learning Technologies & EDULEARN & 40 \\
\hline (5) International Scientific Conference on e-learning and Software for Education & eLSE & 24 \\
\hline (6) IEEE Global Engineering Education Conference & IEEE EDUCON & 18 \\
\hline (7) Learning Media and Technology & Learn. Media Technol. & 15 \\
\hline (8) Conference on Learning Factories & CLF & 14 \\
\hline (9-1) Obrazovanie I Nauka-Education and Science & Obrazov. Nauka & 9 \\
\hline (9-2) Comunicar & Comunicar & 9 \\
\hline (10-1) Dds-Die Deutsche Schule & DDS-Dtsch. Sch. & 8 \\
\hline (10-2) Modern Journal of Language Teaching Methods & Mod. J. Lang. Teach. & 8 \\
\hline (11-1) Information Technologies and Learning Tools & Inf. Technol. Learn. & 6 \\
\hline $\begin{array}{l}\text { (11-2) Russian Scientific and Practical Conference on Planning and Teaching } \\
\text { Engineering Staff for the Industrial and Economic Complex of the Region }\end{array}$ & Russian PTES & 6 \\
\hline (11-3) Dilemas Contemporaneos-Educacion Politica Y Valores & Dilemas Contemp.-Educ & 6 \\
\hline (11-4) Education and Information Technologies & Educ. Inf. Technol. & 6 \\
\hline (12-1) European Educational Research Journal & Eur. Educ. Res. J. & 5 \\
\hline (12-2) Journal of Education Policy & J. Educ. Policy & 5 \\
\hline (12-3) E-Mentor & E-Mentor & 5 \\
\hline (12-4) 4Th Conference on Gender and IT & GenderIT & 5 \\
\hline
\end{tabular}

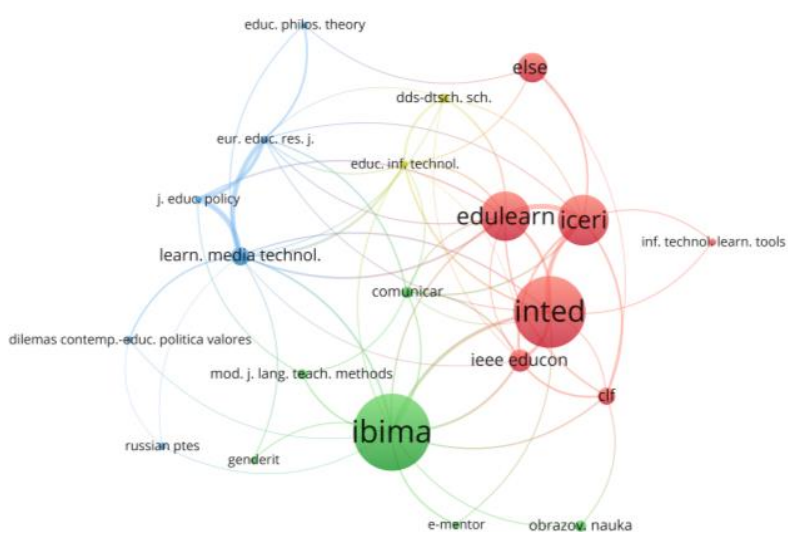

Figure 2 Visualization of top publication sources based on bibliographic coupling relationship network. 
Table 2 Detailed information of top publication sources based on bibliographic coupling relationship network

\begin{tabular}{llll}
\hline Cluster (of disciplines) & \multicolumn{1}{c}{ Publication Venues (with ranking) } & \multicolumn{1}{c}{ Top Keywords (with no. of occurrences) } \\
\hline \multirow{2}{*}{ E1 } & Education \& & (2) INTED, (3) ICERI, (4) EDULEARN, (5) eLSE, (6) & Digitalization (33), digitization (15), digital \\
& Engineering & IEEE EDUCON, (8) CLF, (11-1) Inf. Technol. Learn. Tools & transformation (6) \\
& Education, & (1) IBIMA, (9-1) Obrazov. Nauka, (9-2) Comunicar, (10-2) & digital transformation (19), digital economy \\
\#2 & Management \& & Mod. J. Lang. Teach. Methods, (12-3) E-Mentor, (12-4) & (17), digitalization (13) \\
& Communication & GenderIT & \\
\#3 & Education \& & (7) Learn. Media Technol., (11-2) Russian PTES, (11-3) & Datafication (10), digitization (4), digitalization \\
& Engineering & Dilemas Contemp.-Educ. Politica Valores, (12-1) Eur. Educ. (3), digital transformation (2) & \\
& Res. J., (12-5) Educ. Philos. Theory, (12-2) J. Educ. Policy & Digitization (4), blended learning (2) \\
\hline
\end{tabular}

Cluster \#1, shown center right in Figure 2, colored red, occupy the prominent position of the bibliographic coupling relationship network. Table 2 indicates the research cluster as "Education \& Engineering" in the first row, with key publication venues such as (2) INTED, (3) ICERI, (4) EDULEARN, (5) eLSE, (6) IEEE EDUCON, etc. The top keywords discussed in the cluster include digitalization, digitization, and digital transformation.

Cluster \#2, shown towards the bottom of Figure 2 colored green, is dominated by the top publication venue IBIMA. Table 2 shows that it contains largely "Education, Management \& Communication" publication venues such as (1) IBIMA, (9-2) Comunicar, (10-2) Mod. J. Lang. Teach. Methods, (12-4) GenderIT, etc. The top keywords discussed in the cluster include digital transformation, digital economy, and digitalization.

Cluster \#3, "Education \& Engineering", in the upper left area of Figure 2, colored blue, is dominated by the top journal (7) Learn. Media Technol, along with other journals such as (12-1) Eur. Educ. Res. J., (12-2) J. Educ. Policy, etc. The top keywords include datafication, digitization, digitalization, and digital transformation.

Cluster \#4, the "Education" cluster, shown in the upper middle of Figure 2 colored yellow, is at the intersection of almost all other clusters, with top venues such as (10-1) DDS-Dtsch. Sch., (11-4) Educ. Inf. Technol. The top keywords include digitization, and blended learning.

\subsection{Keyword co-occurrence maps}

With the aim of exploring how different the related concepts are - digitization, digitalization, digital transformation and datafication - the researchers created a series of keyword cooccurrence maps for respective notions of digitization.

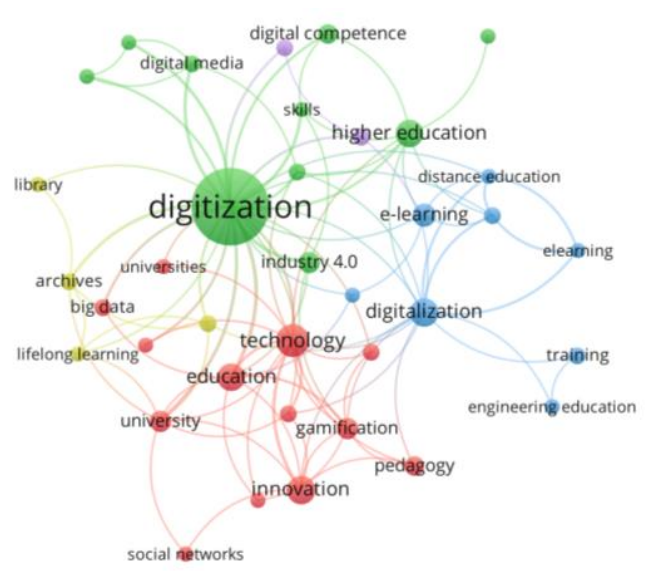

(a)

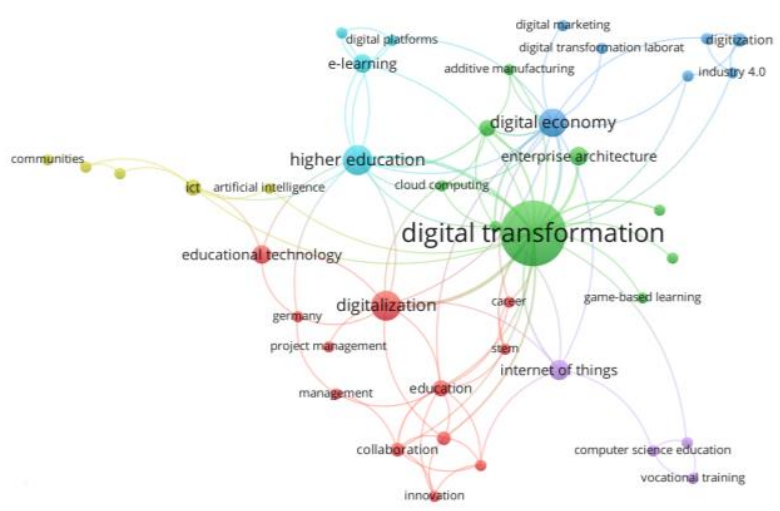

(b)

Figure 3 Keyword co-occurrence maps (based on author keywords): (a) digitization and digitalization (b) digital transformation and datafication

Figure 3 (a) shows the digitization and digitalization map, from e-learning and distance education to virtual classrooms and big data, through to the digitalization of learning to upgrading learning skills[9][10]. It shows that digitization and digitalization have brought about unprecedented changes to the modern education system.

Figure 3 (b) shows the digital transformation and datafication map, suggesting that digital transformation involves not merely content digitization, but also wider topics on the ecosystems of learners and learning 
commitments. Such commitments are especially critical at the intersections of organizations and technologies, and on pressing topics such as educational and cultural resources for skills and future jobs. The findings of systematic mapping provide as part of the roadmap for educators, researchers, and policymakers to identify opportunities and challenges for sustainable and positive change.

\subsection{Emerging concepts}

Overall, the concepts of digital transformation and datafication have emerged across disciplines such education, communication, and management, as shown in the cluster \#2 and \#3 in Table 2 respectively. These emerging concepts clearly relate to the increasingly digitalized world, as shown by the connections to digital economy, digital manufacturing, industry 4.0 , and digital marketing, etc., as shown in Figure 3. Thus, the findings reaffirm the importance of digital competencies and capabilities for sustainable livelihood.

It is then perhaps beneficial to discuss our preliminary observations about how the related concepts are discussed in the literature. First, 'digitization' and 'digitalization' are often used as synonyms. Nonetheless, a distinction can be made between them. The term 'digitization' often refers to the technological processes of converting non-digital resources into digital resources, often as OER. The term 'digitalization' sometimes takes on a broader content to include the digital workflows or processes. Finally, the notion of 'digital transformation' requires more than just resources and processes. It often suggests a more systematic socio-technical changes made possible (but not always) by resources and workflows that are increasingly digitalized.

\section{CONCLUSION}

Our systematic review suggests the increasingly important role of organization and people in adopting digital technologies. Whilst relatively small and sparse compared to the conventional concepts of digitization and digitalization, the rapidly-growing discussions on digital transformation and datafication since 2015 signal a change in research attention from technology-centric concerns to people-centric ones. Thus, it becomes important to continue to raise a similar question on the emerging topics of digital transformation and datafication: how can we facilitate the delivery of sustainable livelihoods and lifestyles through better education and workforce training through the provisions of digital competencies.

Especially when responding to the disruption of COVID-19 outbreak in education and livelihood, policymakers and researchers must pay attention not only to the digital technologies but also the social and organizational dynamics to ensure inclusive and equitable outcomes. The outbreak makes imperative and urgent the need for digital transformation. Thus, we should keep demanding that such transformation be inclusive and equitable.

The digital transformation and datafication aspects of our everyday life present new challenges and demand renewed

\section{ACKNOWLEDGMENT}

The research is funded by a project of HCI for Education Development (2018WQNCX283), under the Major Projects of Guangdong "Young Innovative Talents", and "Information Visualization Design" (NFU 02-40250), both under the Guangdong Department of Education 2018 Grants.

\section{REFERENCES}

[1] M. Oberländer, A. Beinicke, T. Bipp, Digital competencies: A review of the literature and applications in the workplace, Computers \& Education. 146 (2020). https://doi.org/10.1016/j.compedu.2019.103752.

[2] UNESCO, Open Educational Resources (OER), Building Knowledge Societies UNESCO. (2002). https://en.unesco.org/themes/building-knowledgesocieties/oer (accessed April 4, 2020).

[3] T. James, Digital Transformation for Greater Inclusion and Rights, (2019).

[4] UNESCO, Global Education Coalition, Global Education Coalition UNESCO. (2020).

https://en.unesco.org/covid19/educationresponse/global coalition (accessed April 8, 2020).

[5] UNESCO, Distance learning solutions, Global Education Coalition UNESCO. (2020).

https://en.unesco.org/covid19/educationresponse/solutio ns (accessed April 5, 2020).

[6] L. Susan, E. Kweilin, H. Bryan, M. James, Lives and livelihoods: Assessing the near-term impact of COVID-19 on US workers, McKinsey Company, 2020. https://www.mckinsey.com/industries/publicsector/our-insights/lives-and-livelihoods-assessing-thenear-term-impact-of-covid-19-on-us-workers.

[7] B. Marr, How The COVID-19 Pandemic Is FastTracking Digital Transformation In Companies, Forbes. (2020).

https://www.forbes.com/sites/bernardmarr/2020/03/17/ how-the-covid-19-pandemic-is-fast-tracking-digitaltransformation-in-companies/ (accessed April 3, 2020). 
[8] O. Persson, The Intellectual Base and Research Fronts of JASIS 1986-1990, Journal of the American Society for Information Science. 45 (1994) 31-38.

[9] R. Castro, Blended learning in higher education: Trends and capabilities, Educ Inf Technol. 24 (2019) 2523-2546. https://doi.org/10.1007/s10639-019-09886-3.

[10]D.E. Froehlich, Non-Technological Learning Environments in a Technological World: Flipping Comes To The Aid, N.Appr.Ed.R. 7 (2018) 88-92. https://doi.org/10.7821/naer.2018.7.304.

[11]S. Hartong, Between assessments, digital technologies and big data: The growing influence of "hidden" data mediators in education, European Educational Research Journal, European Educational Research Journal. 15 (2016) 523-536. https://doi.org/10.1177/1474904116648966.

[12]P. Johanes, C. Thille, The heart of educational data infrastructures $=$ Conscious humanity and scientific responsibility, not infinite data and limitless experimentation, Br J Educ Technol. 50 (2019) 29592973. https://doi.org/10.1111/bjet.12862. 